\title{
An update on angiogenesis targeting in head and neck squamous cell carcinoma
}

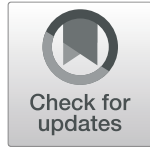

Ida Micaily, Jennifer Johnson and Athanassios Argiris ${ }^{*}$

\begin{abstract}
Angiogenesis is an integral aspect of the growth and proliferation of solid tumors, including head and neck squamous cell carcinoma (HNSCC), and has potential implications in prognosis and treatment of both localized and recurrent/metastatic HNSCC. Therefore, there has been a significant interest in utilizing anti-angiogenic agents either alone or in combination with currently approved and emerging therapies. A phase III randomized trial (E1305) of chemotherapy with or without bevacizumab in the first-line treatment of recurrent/metastatic HNSCC showed an increased response rate and longer progression-free survival but fell short in demonstrating a statistically significant improved survival with bevacizumab. Moreover, toxicity, especially bleeding, was increased. Nevertheless, the study of other anti-angiogenic agents and novel combinations with other therapies, including immunotherapy, remains of interest. Several clinical trials are currently underway.
\end{abstract}

Keywords: Angiogenesis, HNSCC, Bevacizumab, VEGF, VEGFR, EGFR, TKI, Monoclonal antibodies

\section{Introduction}

Tumor growth, proliferation, and metastasis require the process of angiogenesis for nutrient delivery and growth. The formation of new blood vessels can be a ratelimiting step in the development of solid tumors. Without a critical amount of new blood vessel formation known as the angiogenic switch, tumors are unable to grow past a few millimeters in size. Therefore, angiogenesis is an attractive target in cancer therapy across multiple tumor types. Clinical benefit with anti-angiogenics has been modest, but interest in angiogenesis as a therapeutic target remains $[1,2]$.

\section{Targeting angiogenesis in solid tumor malignancies}

Angiogenesis is a complex and highly regulated phenomenon that is co-opted by solid tumor malignancies. Regulation within the tumor microenvironment includes activation of receptor tyrosine kinases such as the vascular endothelial growth factor receptor (VEGFR), epidermal growth factor receptor (EGFR), fibroblast

* Correspondence: Athanassios.Argiris@jefferson.edu

Department of Medical Oncology, Thomas Jefferson University, 1025 Walnut Street, Suite 700, Philadelphia, PA, USA growth factor receptor (FGFR), and platelet-derived growth factor receptors (PDGFR) [3]. Preclinical data has demonstrated that VEGF contributes to immune suppression in multiple ways: by binding to VEGFR1 on myeloid derived stem cells and preventing their differentiation into mature immune cells, by inducing programmed death-ligand 1 (PD-L1) expression on dendritic cells which leads to decreased $\mathrm{T}$ cell activation, by decreasing $\mathrm{T}$ cell adhesion and extravasation through vessel walls, and by increasing Treg differentiation [4-7]. While the majority of research in anti-angiogenics has been directed towards VEGF, other pathways play a critical role that may be exploited clinically. Therefore, combining anti-angiogenics with immune checkpoint inhibitors is of clinical interest in many tumor types. Antiangiogenic strategies are already the standard of care in a variety of malignancies including adenocarcinoma of the colon, non-squamous non-small cell lung cancer (NSCLC), renal cell carcinoma, cervical cancer, glioblastoma multiforme, ovarian cancer, hepatocellular carcinoma, soft tissue sarcoma, and gastric cancer. As of yet, there are no FDA-approved anti-angiogenics in HNSCC.

(c) The Author(s). 2020 Open Access This article is licensed under a Creative Commons Attribution 4.0 International License, which permits use, sharing, adaptation, distribution and reproduction in any medium or format, as long as you give appropriate credit to the original author(s) and the source, provide a link to the Creative Commons licence, and indicate if changes were made. The images or other third party material in this article are included in the article's Creative Commons licence, unless indicated otherwise in a credit line to the material. If material is not included in the article's Creative Commons licence and your intended use is not permitted by statutory regulation or exceeds the permitted use, you will need to obtain permission directly from the copyright holder. To view a copy of this licence, visit http://creativecommons.org/licenses/by/4.0/. 


\section{Rationale for targeting angiogenesis in HNSCC}

The interest in expanding the role of anti-angiogenics into HNSCC is rationally based. Up to $90 \%$ of HNSCC highly express angiogenesis factors like VEGF. High expression is correlated with more advanced disease, resistance to traditional cytotoxic agents, and poor prognosis [8-10]. Similarly, EGFR has been shown to be upregulated in $70-100 \%$ of HNSCC and is also correlated with poor prognosis [11, 12]. Preclinical models have provided evidence to support the targeting of angiogenic pathways in HNSCC $[13,14]$.

\section{Overview of anti-angiogenic agents}

There are currently 14 different FDA-approved antiangiogenic therapies that fall into 4 categories based on mechanism of action: ligand-directed antibodies, receptordirected antibodies, small molecule inhibitors, and immunomodulatory agents, though this class has been relegated to the treatment of multiple myeloma.

The first-in-class ligand-directed anti-angiogenic drug is bevacizumab, a monoclonal antibody targeting VEGFA. It was initially approved in 2004 for the treatment of colorectal cancer and has been approved to date in the treatment of 6 different solid tumors (colorectal cancer, NSCLC, glioblastoma, kidney cancer, ovarian cancer and cervical cancer). Ziv-aflibercept, a recombinant fusion protein composed of the VEGF-binding portion of VEGFR- 1 and -2 acts as a ligand trap, preventing binding and activation of the intended VEGFR targets. This agent has been approved only in combination with chemotherapy for colorectal cancer. Dalantercept is an experimental agent comprised of activin receptor-like kinase 1 fused to a human Fc domain (ALK1-Fc) that binds to ligands such as BMP9 and 10. When bound to its ligands, ALK1-mediated angiogenesis is inhibited.

The first-in-class receptor-directed drug is ramucirumab, a monoclonal antibody targeting VEGFR2. This agent has been developed for the treatment of multiple solid tumors and has gained regulatory approval in NSCLC, gastric cancer, colorectal cancer, and hepatocellular carcinoma.

In contrast to the monoclonal antibodies, tyrosine kinase inhibitors (TKIs) are small molecules that can function by inhibiting multiple targets within angiogenic signaling pathways, including VEGFRs, EGFR, FGFR, and PDGFRs. Examples of TKIs that are utilized for their inhibition of multiple angiogenic receptors include sorafenib, sunitinib, vandetanib, pazopanib, axitinib, regorafenib, lenvatinib, cabozantinib (Table 1). While there is great interest in using VEGFR TKIs in HNSCC, none of these agents have been tested in phase III trials in HNSCC yet.

Development of these antibodies and TKIs in HNSCC has occurred as monotherapy as well as through combinations with other modalities and therapeutic agents:
Table 1 FDA approved anti-angiogenic agents for the treatment of solid tumors

\begin{tabular}{|c|c|c|}
\hline AGENT & DRUG CLASS & MOLECULAR TARGETS \\
\hline Bevacizumab & $\begin{array}{l}\text { Monoclonal } \\
\text { Antibody }\end{array}$ & VEGF \\
\hline Ramucirumab & $\begin{array}{l}\text { Monoclonal } \\
\text { Antibody }\end{array}$ & VEGFR2 \\
\hline Ziv-Aflibercept & $\begin{array}{l}\text { Fusion } \\
\text { Protein }\end{array}$ & VEGF, VEGF-B, PIGF \\
\hline Sorafenib & TKI & $\begin{array}{l}\text { RAF/MEK/ERK, VEGFR } \\
1-3, \text { PDGFR- } \beta \text {, c-KIT, } \\
\text { FLT3, RET }\end{array}$ \\
\hline Sunitinib & TKI & $\begin{array}{l}\text { VEGFR1 and 2, PDGFR-a } \\
\text { and }-\beta, c-K I T, \text { RET, CSF1R, } \\
\text { FLT3 }\end{array}$ \\
\hline Vandetanib & TKI & VEGFR2 and 3, EGFR, RET \\
\hline Pazopanib & TKI & $\begin{array}{l}\text { VEGFR 1-3, PDGFR- } \alpha \text { and } \\
-\beta, \text { FGFR-1 and - } 3, c-K I T\end{array}$ \\
\hline Axitinib & TKI & $\begin{array}{l}\text { VEGFR 1-3, PDGFR- } \alpha \text { and } \\
-\beta, c-K I T\end{array}$ \\
\hline Regorafenib & TKI & VEGFR1-3 \\
\hline Lenvatinib & TKI & $\begin{array}{l}\text { VEGR1-3, FGFR1-4, PDGFR- } \\
\text { a, c-KIT, RET }\end{array}$ \\
\hline Cabozatinib & TKI & $\begin{array}{l}\text { VEGFR2, AXL, RET, MET, c-KIT, } \\
\text { FLT-3 }\end{array}$ \\
\hline
\end{tabular}

TKI tyrosine kinase inhibitor

chemotherapy, radiotherapy, molecularly targeted therapy, and more recently immunotherapy.

\section{TKls and other agents}

TKIs have demonstrated preclinical activity against angiogenesis through multiple receptors, however these agents have yielded varying degrees of success when used for the treatment of patients with recurrent/metastatic HNSCC (Table 2) [15-23]. Sorafenib is a multi-kinase inhibitor that has been evaluated as a single-agent in recurrent/ metastatic HNSCC. Phase II data showed a low likelihood of response to sorafenib in this setting $[15,16]$. Sunitinib, a multi-TKI with activity against PDGFRs and VEGFRs showed similarly minimal response rates in phase II studies [17-19]. Bleeding complications and skin ulceration/ fistula formation were seen in some of these studies [16, 17]. A phase II trial of axitinib demonstrated a low objective response rate but favorable disease control rate of $77 \%$ and median overall survival (OS) of 10.9 months with acceptable toxicity profile [20]. Combinations of TKIs with chemotherapy as well as cetuximab have also been studied in two randomized phase II trials without encouraging results $[21,22]$. A notable exception was a single arm phase II trial of carboplatin, paclitaxel and sorafenib that reported promising efficacy with this combination regimen with a response rate of $55 \%$, median progression-free survival (PFS) of 8.5 months and median OS of 22.6 months 
Table 2 VEGFR tyrosine-kinase inhibitors studied as monotherapy or combination therapy in HNSCC

\begin{tabular}{|c|c|c|c|c|}
\hline AGENTS & STUDY DESIGN/PHASE & $\begin{array}{l}\text { \# of } \\
\text { PATIENTS }\end{array}$ & PRIMARY ENDPOINT/OTHER EFFICACY ENDPOINTS & REFERENCE \\
\hline \multicolumn{5}{|l|}{ Sorafenib } \\
\hline $\begin{array}{l}\text { Sorafenib } 400 \mathrm{mg} \\
\text { twice daily }\end{array}$ & $\begin{array}{l}\text { Single arm, Phase II } \\
\text { Single arm, Phase II }\end{array}$ & $\begin{array}{l}n=41 \\
n=27\end{array}$ & $\begin{array}{l}\text { RR 2\%; median PFS } 4 \text { mo; median OS } 9 \text { mo } \\
\text { RR 4\%; median PFS } 1.8 \text { mo; median OS } 4.2 \text { mo }\end{array}$ & $\begin{array}{l}\text { Williamson, } 2010 \\
\text { [15] } \\
\text { Elser, } 2007 \text { [16] }\end{array}$ \\
\hline \multicolumn{5}{|l|}{ Sunitinib } \\
\hline Sunitinib 37.5 mg daily & Single arm, Phase II & $n=38$ & $\begin{array}{l}\text { Rate of disease control 50\%; RR 3\%; median PFS } 2 \text { mo; } \\
\text { median OS } 3.4 \text { mo }\end{array}$ & Machiels, 2010 [17] \\
\hline $\begin{array}{l}\text { Sunitinib } 50 \mathrm{mg} \text { daily } \\
\text { for } 4 \text { weeks on, } 2 \text { weeks off }\end{array}$ & $\begin{array}{l}\text { Single arm, Phase II } \\
\text { (two cohorts, cohort } \\
\text { A: PS 0-1 cohort B: PS 2) }\end{array}$ & $n=22$ & $\begin{array}{l}\text { Cohort A: RR 8\%; median TTP } 2 \text { mo; median OS } 4.9 \text { mo } \\
\text { Cohort B: RR 0; median TTP } 2.5 \text { mo; median OS } 4.5 \text { mo }\end{array}$ & Choong, 2010 [18] \\
\hline $\begin{array}{l}\text { Sunitinib } 50 \mathrm{mg} \text { daily for } \\
4 \text { weeks on, } 2 \text { weeks off }\end{array}$ & Single arm, Phase II & $n=17$ & RR 0; median TTP 2.3 mo; median OS 4 mo & $\begin{array}{l}\text { Fountzilas, } 2010 \\
\text { [19] }\end{array}$ \\
\hline \multicolumn{5}{|l|}{ Axitinib } \\
\hline Axitinib 5 mg twice daily & Single arm, Phase II & $n=30$ & $\begin{array}{l}\text { 6-month PFS 30\%; RR 7\%; median PFS } 3.7 \text { months; } \\
\text { median OS } 10.9 \text { mo }\end{array}$ & $\begin{array}{l}\text { Swiecicki, } 2015 \\
\text { [20] }\end{array}$ \\
\hline \multicolumn{5}{|l|}{ Combination Therapy } \\
\hline Cetuximab +/- sorafenib & Randomized, Phase II & $n=55$ & $\begin{array}{l}\text { Median PFS } 3 \text { mo (cetuximab arm) and } 3.2 \text { mo } \\
\text { (combination arm) }\end{array}$ & Gilbert, 2015 [21] \\
\hline Docetaxel +/- vandetanib & Randomized, Phase II & $n=29$ & RR 7\% (docetaxel arm) and 13\% (combination arm) & Limaye, 2013 [22] \\
\hline $\begin{array}{l}\text { Carboplatin, paclitaxel, } \\
\text { sorafenib }\end{array}$ & Single arm, Phase II & $n=48$ & Median PFS 8.5 mo; RR 55\%; median OS 22.6 mo & $\begin{array}{l}\text { Blumenschein, } \\
2012[23]\end{array}$ \\
\hline
\end{tabular}

$R R$ overall response rate, PFS progression-free survival, TTP time to progression, $P S$ performance status, mo months

[23]. No randomized trials of chemotherapy with or without sorafenib have been conducted so far in HNSCC.

Dalantercept, an ALK1-Fc trap, was evaluated in a phase II monotherapy study in recurrent/metastatic HNSCC. In 40 evaluable patients the median PFS was 1.4 months and the median OS 7.1 months. While the drug was well tolerated, these results were not encouraging [24].

\section{Bevacizumab with chemotherapy in recurrent/metastatic HNSCC}

Bevacizumab has been combined with chemotherapy in clinical trials (Table 3 ). In a phase II trial in the first-line treatment of recurrent/metastatic HNSCC that enrolled 40 patients, bevacizumab was combined with the antimetabolite pemetrexed [25]. This regimen resulted in a median time to progression of 5 months, median OS of 11.3 months and an overall response rate of $30 \%$. Fifteen percent of patients had grade 3-5 bleeding events but otherwise the regimen was well tolerated. These efficacy results were comparable to historical controls using the 3-drug standard "EXTREME" regimen (platinum, 5-FU and cetuximab) [35].

A phase III randomized clinical trial (E1305) of bevacizumab in patients with recurrent/metastatic HNSCC was conducted by the ECOG-ACRIN Cancer Research Group [26]. The E1305 trial randomly assigned patients to receive an investigator's-choice platinum doublet (cisplatin or carboplatin plus either docetaxel or 5fluorouracil) with or without the addition of bevacizumab. Patients in this study had not received therapy for recurrent/metastatic disease but prior chemotherapy or cetuximab was allowed if given in the setting of prior potentially curative treatment with an interval of at least 4 months. In a total of 403 patients accrued, the median OS was 12.6 months with bevacizumab and chemotherapy versus 11 months with chemotherapy alone, a difference that was not statistically significant (HR 0.87, 95\% CI $0.70-1.0, p=0.22$ ). Although the primary endpoint of the study was not met, there was a numerical survival advantage at 2, 3 and 4 years in the bevacizumab arm (25.2\% vs $18.1 \%$ at 2 years, $16.4 \%$ vs $10 \%$ at 3 years, and $11.8 \%$ vs $6.4 \%$ at 4 years for chemotherapy plus bevacizumab versus chemotherapy alone). Moreover, median PFS improved from 4.3 months to 6.0 months with the addition of bevacizumab to chemotherapy (HR $0.71 ; p=$ $0.0012)$, and the overall response rate increased from 24.5 to $35.5 \%(p=0.013)$. However, patients experienced more treatment-related toxicities with bevacizumab, particularly grade 3-5 bleeding. While this study provides evidence of improved antitumor activity with the addition of an anti-angiogenic agent to chemotherapy, randomized data showing survival benefit with this approach are still lacking. The study of better-tolerated anti-angiogenic agents in combination with chemotherapy or other targeted agents is warranted. Better patient 
Table 3 Bevacizumab-containing combination therapies in HNSCC

\begin{tabular}{|c|c|c|c|c|}
\hline AGENTS COMBINED WITH BEVACIZUMAB & STUDY DESIGN/PHASE & \#Of PATIENTS & PRIMARY EFFICACY ENDPOINT & AUTHOR \\
\hline \multicolumn{5}{|l|}{ Chemotherapy } \\
\hline Pemetrexed + bevacizumab & Single arm, Phase II & $n=47$ & Median TTP 5 months & $\begin{array}{l}\text { Argiris, } \\
2011[25]\end{array}$ \\
\hline $\begin{array}{l}\text { Chemotherapy +/- bevacizumab } \\
\text { (chemotherapy was investigator's choice: } \\
\text { cisplatin+ 5-FU, cisplatin+docetaxel, } \\
\text { carboplatin+ 5-FU, or carboplatin+ docetaxel) }\end{array}$ & Randomized, Phase III & $n=403$ & $\begin{array}{l}\text { Median overall survival } 12.6 \text { months } \\
\text { with bevacizumab and } 11 \text { months } \\
\text { without bevacizumab ( } p=0.13 \text { ) }\end{array}$ & $\begin{array}{l}\text { Argiris, } \\
2019[26]\end{array}$ \\
\hline \multicolumn{5}{|l|}{ Chemoradiotherapy } \\
\hline RT + docetaxel + bevacizumab & Single arm, Phase II & $n=30$ & 3-year PFS 62\% & $\begin{array}{l}\text { Yao, } \\
2015[27]\end{array}$ \\
\hline RT + cisplatin + bevacizumab & Single arm, Phase II & $n=42$ & 2-year PFS 76\% & $\begin{array}{l}\text { Fury, } \\
2012[28]\end{array}$ \\
\hline RT + 5-FU, hydroxyurea + bevacizumab & Randomized, Phase II & $n=26$ & $\begin{array}{l}\text { 2-year OS } 58 \% \text { with bevacizumab } \\
\text { and } 89 \% \text { without bevacizumab }\end{array}$ & $\begin{array}{l}\text { Salama, } \\
2011[29]\end{array}$ \\
\hline \multicolumn{5}{|l|}{ EGFR inhibitor } \\
\hline Cetuximab + bevacizumab & Single arm, Phase II & $n=46$ & RR $16 \%$ & $\begin{array}{l}\text { Argiris, } \\
2013[30]\end{array}$ \\
\hline Erlotinib + bevacizumab & Single arm, Phase $1 / \|$ & $\begin{array}{l}\text { Phase I } n=10 \\
\text { Phase II } \mathrm{n}=48\end{array}$ & Median PFS 4.1 months & $\begin{array}{l}\text { Cohen, } \\
2009 \text { [31] }\end{array}$ \\
\hline \multicolumn{5}{|l|}{ Chemoradiotherapy + EGFR inhibitor } \\
\hline $\begin{array}{l}\text { RT + pemetrexed + cetuximab +/- } \\
\text { bevacizumab }\end{array}$ & Randomized, Phase II & $n=78$ & $\begin{array}{l}\text { 2-year PFS } 75 \% \text { with bevacizumab } \\
\text { and } 79 \% \text { without bevacizumab }\end{array}$ & $\begin{array}{l}\text { Argiris, } \\
2016 \text { [32] }\end{array}$ \\
\hline RT + cisplatin + cetuximab + bevacizumab & Single arm, Phase II & $n=30$ & 2-year PFS 88.5\% & $\begin{array}{l}\text { Fury, } \\
2016[33]\end{array}$ \\
\hline $\begin{array}{l}\text { Paclitaxel+ carboplatin+ 5-FU + bevacizumab, } \\
\text { followed by RT + paclitaxel + erlotinib + } \\
\text { bevacizumab }\end{array}$ & Single arm, Phase II & $n=60$ & 3-year PFS 71\% & $\begin{array}{l}\text { Hainsworth, } \\
2011[34]\end{array}$ \\
\hline
\end{tabular}

$R T$ radiotherapy, $R R$ overall response rate, OS overall survival, PFS progression-free survival, $T T P$ time to progression

selection on the basis of molecular biomarkers may contribute to optimal results.

\section{Anti-angiogenics with EGFR inhibitors in recurrent/ metastatic HNSCC}

EGFR blockade has also been a desired therapeutic target due to the proposed mechanism of preventing VEGF escape [36]. Cetuximab, a monoclonal antibody against EGFR, has been approved by the FDA for the treatment of HNSCC as monotherapy and in combination with radiotherapy or chemotherapy $[35,37,38]$. Cetuximab has been studied in combination with bevacizumab in many clinical trials. Preclinical data supported the clinical evaluation of this combination in HNSCC [30]. Argiris et al. conducted a phase II trial that investigated cetuximab plus bevacizumab in recurrent/metastatic HNSCC. Up to 1 prior regimen for recurrent/metastatic disease was allowed. The response rate of $16 \%$, median PFS of 2.8 months and the median OS of 7.5 months appeared promising [30]. Another trial by Cohen et al. evaluated the combination of an EGFR TKI, erlotinib and bevacizumab in a similar patient population. They reported a response rate of $15 \%$, median PFS of 4.1 months, and median OS of 7.1 months [31]. Both trials reported an acceptable rate of bleeding events (grade 35 bleeding of $4-5 \%$ ). A previously mentioned phase II randomized trial failed to show improved efficacy with the addition of sorafenib to cetuximab [21]. A more recent phase Ib trial reported promising results with pazopanib and cetuximab in patients with recurrent/ metastatic HNSCC [39]. However, appropriately designed randomized trials would be required to fully assess the potential role of these combination treatments in HNSCC.

\section{Bevacizumab with chemoradiotherapy or chemoradiotherapy plus EGFR inhibitors}

Radiotherapy and chemotherapy are speculated to work synergistically with anti-angiogenics [40]. Therefore, anti-angiogenic combinations with chemoradiotherapy have been tested in clinical trials (Table 3). A phase I trial evaluated the combination of bevacizumab with 5$\mathrm{FU}$, hydroxyurea, and radiotherapy for patients with recurrent or poor prognosis HNSCC with a goal of finding the maximum tolerated dose of bevacizumab [41]. Twothirds of the patients had been previously irradiated. Investigators determined that the adverse effects in this patient subset were comparable to historically re-irradiated 
controls. With a median OS for re-irradiated patients of 10.3 months, the antitumor effect was sufficient to support further interest in combinations of bevacizumab with radiotherapy. However, a subsequent phase II randomized trial in locally advanced HNSCC with twicedaily radiotherapy, hydroxyurea, 5-FU with or without bevacizumab was terminated due to unexpectedly higher locoregional progression rate and worse two-year survival in the bevacizumab arm [29].

The incorporation of bevacizumab into a more widely used platinum-based chemoradiotherapy regimen was also tested. In a phase II trial bevacizumab was added to concurrent chemoradiotherapy with high-dose cisplatin given in split doses (days 1, 2, 22, 23, 43, and 44) and 70 Gy of intensity-modulated radiation therapy (IMRT) [28]. Forty-two patients with previously untreated disease (93\% with an oropharyngeal primary, $45 \%$ of whom confirmed positive for human papillomavirus) were enrolled and treated. The 2-year PFS was $76 \%$ and the 2year OS was $88 \%$ which was promising and the toxicity profile was acceptable.

A phase II trial in locally advanced HNSCC examined the addition of bevacizumab to radiotherapy and docetaxel in 30 patients (67\% with an oropharyngeal primary) and reported a 3-year PFS of $62 \%$ and a 3-year OS of $68 \%$ [27], whereas another phase II trial evaluated the addition of bevacizumab to an induction chemotherapy regimen and subsequent concurrent chemoradiotherapy [34]. In the latter trial, patients $(60 \%$ had an oropharyngeal primary) were treated with a novel neoadjuvant approach of 6 weeks of paclitaxel, carboplatin, 5-FU, and bevacizumab before continuing with concurrent radiotherapy with paclitaxel, bevacizumab, and erlotinib. The 2-year and 3-year PFS was 83 and 71\%, respectively, and the 2-year and 3-year OS was 90 and $82 \%$, respectively, and no unanticipated toxicities were seen [34].

Other trials have looked into the incorporation of both bevacizumab and cetuximab in combined modality treatment. A single arm phase II trial of the combination of radiotherapy, cisplatin, cetuximab and bevacizumab that enrolled 30 patients (24 with an oropharyngeal primary, of whom $71 \%$ had human papillomavirus-associated tumors) reported a promising PFS of $88.5 \%$ at 2 years [33]. It is difficult to evaluate the results of single arm studies in locally advanced HNSCC and make comparisons with historical controls because of many potential biases and the variability in inclusion of good prognosis patients (e.g. those with human papillomavirus positive oropharyngeal tumors). A phase II randomized trial that evaluated the addition of bevacizumab in a combined modality regimen in 78 patients with previously untreated locally advanced HNSCC was conducted by Argiris et al [32] Patients received IMRT 70 Gy with concurrent cetuximab and pemetrexed, with or without bevacizumab. The two-year PFS was not different with or without bevacizumab (75\% versus $79 \%$ ). Moreover, this study demonstrated increased toxicities in patients treated with bevacizumab [32].

Overall, current evidence does not support added benefit from the combination of anti-angiogenics and EGFR-inhibitors in locally advanced HNSCC. Further evaluation of strategies incorporating anti-angiogenenic targets with radiotherapy may be appropriate. Nevertheless, the data so far do not justify the conduct of a phase III trial of anti-angiogenics in locally advanced HNSCC.

\section{Anti-angiogenics with immune checkpoint inhibitors}

Anti-angiogenics in combination with immune checkpoint inhibitors have established benefit in multiple tumor types $[42,43]$. Additionally, the immune checkpoint inhibitors nivolumab and pembrolizumab have both been FDA approved for the treatment of recurrent/metastatic HNSCC. The advantage of combining one of these agents with an anti-angiogenic agent remains unknown in HNSCC, however, it could potentially potentiate a synergistic effect, leading to greater antitumor effect. Mechanistically, antiangiogenic therapies are thought to promote an immunosupportive environment by increasing the trafficking of $T$ cells into tumors and reduce immunosuppressive responses, thereby overcoming resistance to checkpoint inhibitors [44]. Therefore, several ongoing clinical trials are evaluating simultaneous targeting of angiogenesis and tumor immunity. A phase Ia/b multicohort trial studied ramucirumab with the programmed cell death protein 1 (PD-1) inhibitor pembrolizumab with good safety and preliminary efficacy results [45]. A phase Ib/II trial of lenvatinib plus pembrolizumab in patients with multiple solid tumor types, including HNSCC, demonstrated promising preliminary clinical activity in 22 patients with recurrent/ metastatic HNSCC (response rate of $46 \%$ and median PFS of 4.7 months) with expected toxicities [46]. Similar combination strategies are being actively pursued, including ongoing phase II trials of ramucirumab plus pembrolizumab and bevacizumab plus atezolizumab in recurrent/ metastatic HNSCC (NCT03650764, NCT03818061).

\section{Conclusion}

The induction and sustainment of angiogenesis is one of the hallmarks of solid tumors. Various pro-angiogenic factors have been found to be upregulated in HNSCC, correlating with more aggressive disease. Anti-angiogenic agents with differing mechanisms of action have been tested in the treatment of HNSCC with mixed success. The field is open to further investigations of combinations of antiangiogenic agents with immunotherapeutic, molecularly targeted and chemotherapeutic agents in HNSCC. In the future, individualized anti-angiogenic treatment based on molecular tumor characterization will likely lead to improved outcomes. 


\section{Abbreviations}

ALK1-Fc: Activin receptor-like kinase 1 fused to a human Fc domain; EGFR: Epidermal growth factor receptor; FGFR: Fibroblast growth factor receptor; HNSCC: Head and neck squamous cell carcinoma; IMRT: Intensitymodulated radiation therapy; NSCLC: Non-small cell lung cancer; ORR: Overall response rate; OS: Overall survival; PD-1: Programmed cell death protein 1; PDGFR: Platelet-derived growth factor receptors; PFS: Progressionfree survival; PS: Performance status; TKI: Tyrosine kinase inhibitor; TTP: Time to progression; VEGFR: Vascular endothelial growth factor receptor

\section{Acknowledgements}

Not applicable.

Authors' contributions

All authors read and approved the final manuscript.

\section{Funding}

Not applicable.

\section{Availability of data and materials}

Data sharing not applicable to this article as no datasets were generated or analyzed during the current study.

\section{Ethics approval and consent to participate}

Not applicable.

\section{Consent for publication}

Not applicable.

\section{Competing interests}

The authors declare that they have no competing interests.

Received: 24 October 2019 Accepted: 4 March 2020

Published online: 06 April 2020

\section{References}

1. Kim KJ, Li B, Winer J, et al. Inhibition of vascular endothelial growth factorinduced angiogenesis suppresses tumour growth in vivo. Nature. 1993;362: 841-4.

2. Vassilakopoulou M, Psyrri A, Argiris A. Targeting angiogenesis in head and neck cancer. Oral Oncol. 2015;51:409-15.

3. Carmeliet P, Jain RK. Molecular mechanisms and clinical applications of angiogenesis. Nature. 2011;473:298-307.

4. Du R, Lu KV, Petritsch C, et al. HIF1alpha induces the recruitment of bone marrow-derived vascular modulatory cells to regulate tumor angiogenesis and invasion. Cancer Cell. 2008;13:206-20.

5. Murdoch C, Muthana M, Coffelt SB, et al. The role of myeloid cells in the promotion of tumour angiogenesis. Nat Rev Cancer. 2008:8:618-31.

6. Shojaei F, Wu X, Zhong C, et al. Bv8 regulates myeloid-cell-dependent tumour angiogenesis. Nature. 2007:450:825-31.

7. Ziogas AC, Gavalas NG, Tsiatas M, et al. VEGF directly suppresses activation of T cells from ovarian cancer patients and healthy individuals via VEGF receptor type 2. Int J Cancer. 2012;130:857-64.

8. Kyzas PA, Cunha IW, loannidis JP. Prognostic significance of vascular endothelial growth factor immunohistochemical expression in head and neck squamous cell carcinoma: a meta-analysis. Clin Cancer Res. 2005;11: 1434-40.

9. Smith BD, Smith GL, Carter D, et al. Prognostic significance of vascular endothelial growth factor protein levels in oral and oropharyngeal squamous cell carcinoma. J Clin Oncol. 2000;18:2046-52.

10. Mineta $H$, Miura $K$, Ogino $T$, et al. Prognostic value of vascular endothelial growth factor (VEGF) in head and neck squamous cell carcinomas. $\mathrm{Br}$ J Cancer. 2000;83:775-81.

11. Kalyankrishna S, Grandis JR. Epidermal growth factor receptor biology in head and neck cancer. J Clin Oncol. 2006;24:2666-72.

12. Polanska H, Raudenska M, Hudcova K, et al. Evaluation of EGFR as a prognostic and diagnostic marker for head and neck squamous cell carcinoma patients. Oncol Lett. 2016:12:2127-32.

13. Fujita K, Sano D, Kimura M, et al. Anti-tumor effects of bevacizumab in combination with paclitaxel on head and neck squamous cell carcinoma. Oncol Rep. 2007;18:47-51.
14. Hoang T, Huang S, Armstrong E, et al. Enhancement of radiation response with bevacizumab. J Exp Clin Cancer Res. 2012;31:37.

15. Williamson SK, Moon J, Huang CH, et al. Phase II evaluation of sorafenib in advanced and metastatic squamous cell carcinoma of the head and neck: southwest oncology group study S0420. J Clin Oncol. 2010;28:3330-5.

16. Elser $\mathrm{C}$, Siu LL, Winquist $\mathrm{E}$, et al. Phase II trial of sorafenib in patients with recurrent or metastatic squamous cell carcinoma of the head and neck or nasopharyngeal carcinoma. J Clin Oncol. 2007;25:3766-73.

17. Machiels JP, Henry S, Zanetta S, et al. Phase II study of sunitinib in recurrent or metastatic squamous cell carcinoma of the head and neck: GORTEC 2006-01. J Clin Oncol. 2010;28:21-8.

18. Choong NW, Kozloff M, Taber D, et al. Phase II study of sunitinib malate in head and neck squamous cell carcinoma. Investig New Drugs. 2010;28:67783.

19. Fountzilas G, Fragkoulidi A, Kalogera-Fountzila A, et al. A phase II study of sunitinib in patients with recurrent and/or metastatic non-nasopharyngeal head and neck cancer. Cancer Chemother Pharmacol. 2010;65:649-60.

20. Swiecicki PL, Zhao L, Belile E, et al. A phase II study evaluating axitinib in patients with unresectable, recurrent or metastatic head and neck cancer. Investig New Drugs. 2015;33:1248-56.

21. Gilbert J, Schell MJ, Zhao X, et al. A randomized phase II efficacy and correlative studies of cetuximab with or without sorafenib in recurrent and/ or metastatic head and neck squamous cell carcinoma. Oral Oncol. 2015;51: 376-82.

22. Limaye S, Riley S, Zhao S, et al. A randomized phase II study of docetaxel with or without vandetanib in recurrent or metastatic squamous cell carcinoma of head and neck (SCCHN). Oral Oncol. 2013:49:835-41.

23. Blumenschein GR, Glisson BS, Lu C, et al: Final results of a phase II study of sorafenib in combination with carboplatin and paclitaxel in patients with metastatic or recurrent squamous cell cancer of the head and neck $(\mathrm{SCCH}$ N). J Clin Oncol 30, 2012 (suppl; abstr 5592), 2012.

24. Jimeno A, Posner MR, Wirth $L$, et al. A phase 2 study of dalantercept, an activin receptor-like kinase-1 ligand trap, in patients with recurrent or metastatic squamous cell carcinoma of the head and neck. Cancer. 2016; 122:3641-9.

25. Argiris A, Karamouzis MV, Gooding WE, et al. Phase II trial of pemetrexed and bevacizumab in patients with recurrent or metastatic head and neck cancer. J Clin Oncol. 2011:29:1140-5.

26. Argiris A, Li S, Savvides P, et al. Phase III randomized trial of chemotherapy with or without Bevacizumab in patients with recurrent or metastatic head and neck Cancer. J Clin Oncol. 2019;37:3266-74.

27. Yao M, et al. Phase II study of bevacizumab in combination with docetaxel and radiation in locally advanced squamous cell carcinoma of the head and neck. Head Neck. 2015;37:1665-71.

28. Fury MG, Lee NY, Sherman E, et al. A phase 2 study of bevacizumab with cisplatin plus intensity-modulated radiation therapy for stage III/IVB head and neck squamous cell cancer. Cancer. 2012;118:5008-14.

29. Salama JK, Haraf DJ, Stenson KM, et al. A randomized phase II study of 5fluorouracil, hydroxyurea, and twice-daily radiotherapy compared with bevacizumab plus 5-fluorouracil, hydroxyurea, and twice-daily radiotherapy for intermediate-stage and T4N0-1 head and neck cancers. Ann Oncol. 2011;22:2304-9.

30. Argiris A, Kotsakis AP, Hoang $T$, et al. Cetuximab and bevacizumab: preclinical data and phase II trial in recurrent or metastatic squamous cell carcinoma of the head and neck. Ann Oncol. 2013:24:220-5.

31. Cohen EE, Davis DW, Karrison TG, et al. Erlotinib and bevacizumab in patients with recurrent or metastatic squamous-cell carcinoma of the head and neck: a phase I/II study. Lancet Oncol. 2009;10:247-57.

32. Argiris $\mathrm{A}$, Bauman JE, Ohr J, et al. Phase II randomized trial of radiation therapy, cetuximab, and pemetrexed with or without bevacizumab in patients with locally advanced head and neck cancer. Ann Oncol. 2016;27: 1594-600.

33. Fury MG, Xiao H, Sherman EJ, et al. Phase II trial of bevacizumab + cetuximab + cisplatin with concurrent intensity-modulated radiation therapy for patients with stage III/IVB head and neck squamous cell carcinoma. Head Neck. 2016:38(Suppl 1):E566-70.

34. Hainsworth JD, Spigel DR, Greco FA, et al. Combined modality treatment with chemotherapy, radiation therapy, bevacizumab, and erlotinib in patients with locally advanced squamous carcinoma of the head and neck: a phase II trial of the Sarah Cannon oncology research consortium. Cancer J. 2011;17:267-72 
35. Vermorken JB, Mesia R, Rivera F, et al. Platinum-based chemotherapy plus cetuximab in head and neck cancer. N Engl J Med. 2008;359:1116-27.

36. Dey N, De P, Brian LJ. Evading anti-angiogenic therapy: resistance to antiangiogenic therapy in solid tumors. Am J Transl Res. 2015;7:1675-98.

37. Bonner JA, Harari PM, Giralt J, et al. Radiotherapy plus cetuximab for squamous-cell carcinoma of the head and neck. N Engl J Med. 2006;354: 567-78.

38. Vermorken JB, Trigo J, Hitt R, et al. Open-label, uncontrolled, multicenter phase II study to evaluate the efficacy and toxicity of cetuximab as a single agent in patients with recurrent and/or metastatic squamous cell carcinoma of the head and neck who failed to respond to platinum-based therapy. J Clin Oncol. 2007;25:2171-7.

39. Adkins $D$, Mehan P, Ley J, et al. Pazopanib plus cetuximab in recurrent or metastatic head and neck squamous cell carcinoma: an open-label, phase 1b and expansion study. Lancet Oncol. 2018:19:1082-93.

40. Hsu HW, Wall NR, Hsueh CT, et al. Combination antiangiogenic therapy and radiation in head and neck cancers. Oral Oncol. 2014;50:19-26.

41. Seiwert TY, Haraf DJ, Cohen EE, et al. Phase I study of bevacizumab added to fluorouracil-and hydroxyurea-based concomitant chemoradiotherapy for poor-prognosis head and neck cancer. J Clin Oncol. 2008;26:1732-41.

42. Rini Bl, Powles $T$, Atkins MB, et al. Atezolizumab plus bevacizumab versus sunitinib in patients with previously untreated metastatic renal cell carcinoma (IMmotion151): a multicentre, open-label, phase 3, randomised controlled trial. Lancet. 2019;393:2404-15.

43. Socinski MA, Jotte RM, Cappuzzo F, et al. Atezolizumab for first-line treatment of metastatic nonsquamous NSCLC. N Engl J Med. 2018;378: 2288-301.

44. Manegold C, Dingemans AC, Gray JE, et al. The potential of combined immunotherapy and Antiangiogenesis for the synergistic treatment of advanced NSCLC. J Thorac Oncol. 2017;12:194-207.

45. Herbst RS, Arkenau HT, Santana-Davila R, et al. Ramucirumab plus pembrolizumab in patients with previously treated advanced non-small-cell lung cancer, gastro-oesophageal cancer, or urothelial carcinomas (JVDF): a multicohort, non-randomised, open-label, phase 1a/b trial. Lancet Oncol. 2019:20:1109-23.

46. Taylor MH, Lee CH, Makker V, et al. Phase IB/II Trial of Lenvatinib Plus Pembrolizumab in Patients With Advanced Renal Cell Carcinoma, Endometrial Cancer, and Other Selected Advanced Solid Tumors. J Clin Oncol. 2020;2020:JCO1901598. https://doi.org/10.1200/JCO.19.01598. [Epub ahead of print].

\section{Publisher's Note}

Springer Nature remains neutral with regard to jurisdictional claims in published maps and institutional affiliations.

Ready to submit your research? Choose BMC and benefit from:

- fast, convenient online submission

- thorough peer review by experienced researchers in your field

- rapid publication on acceptance

- support for research data, including large and complex data types

- gold Open Access which fosters wider collaboration and increased citations

- maximum visibility for your research: over $100 \mathrm{M}$ website views per year

At $\mathrm{BMC}$, research is always in progress.

Learn more biomedcentral.com/submissions 